\title{
Relationships between Depression, Oral Dryness, and Oral Health-Related Quality of Life among Elderly in Korea
}

\author{
So-Jung Mun, Su-Kyung Park², Ji-Eun $\mathrm{Heo}^{3}$, Da-Yee Jeung ${ }^{4}$, Won-Gyoun Chung ${ }^{1}$, \\ Ma-I Choi ${ }^{2}$, and Hyun-Sun Jeon ${ }^{5, \dagger}$ \\ 'Department of Dental Hygiene, Yonsei University Wonju College of Medicine, Wonju 26426, \\ 2Department of Dental Hygiene, Yonsei University Graduate School, Seoul 03722, \\ ${ }^{3}$ Department of Preventive Medicine and Public Health, Yonsei University College of Medicine, Seoul 03722, \\ ${ }^{4}$ Department of Dental Hygiene, Hanyang Women's Institute of Technology, Seoul 04763, \\ ${ }^{5}$ Department of Dental Hygiene, Yeoju Institute of Technology, Yeoju 12652, Korea
}

\begin{abstract}
Background: This study aimed to analyze correlations between depression, cognitive function, oral health state, ability to perform activities of daily living, oral dryness symptoms, and oral health-related quality of life, and determine factors influencing the latter.

Methods: This was a cross-sectional study based on questionnaires completed by 260 participants with suspected dementia, residing in South Korea. Psychiatrists, psychiatric nurses, and dental hygienists visited clinics in the participating regions for examination and questionnaire administration. General characteristics, the geriatric depression scale, ability to perform activities of daily living, cognitive function, oral health state, and oral health-related quality of life were analyzed. Independent $t$-tests, one-way analysis of variance (ANOVA), correlation analysis and multiple regression analysis were conducted, identifying factors affecting oral health-related quality of life. Data analysis was performed using SPSS ver. 20.0 (IBM Corp., USA), and the significance was set at $\mathrm{p}<0.05$.

Results: Approximately $65.0 \%$ of participants were female, $63.5 \%$ were in their $70 \mathrm{~s}$, and $90.0 \%$ had health insurance. About $21.5 \%, 42.0 \%$, and $36.5 \%$ were normal, slightly impaired, and had dementia, respectively. High cognitive impairment was associated with poor oral health. Sex, education levels, marital status, and living arrangements influenced oral health-related quality of life. According to the regression analysis, geriatric depression and oral dryness affected the Geriatric Oral Health Assessment Index scores.

Conclusion: In conclusion, oral dryness and depression levels among elders influenced oral health-related quality of life. The results showed that to enhance elders' oral health-related quality of life, it is essential to not only improve their oral health state, but also relieve oral health problems, especially oral dryness, and take into consideration their psychological aspects.
\end{abstract}

Key Words: Aged, Cognition, Depression, Oral health, Quality of life

\section{Introduction}

South Korea is an ageing society, with $14.9 \%$ of its population aged $\geq 65$ years. It is expected to become a super-aged society, with an elderly population estimated at $>20 \%$ after 2025. According to the National Statistical Office, the expected lifespan increased to 82.7 years in
$2017^{1)}$. This increase highlights the importance of elderly persons' health, both physical and mental. There is also increasing interest in elders' quality of life.

Quality of life is assessed through self-perceptions of living status in relation to one's culture, value systems, goals, expectations, standards, and interests in one's residential area $^{2}$. It is a multidimensional concept in- 
corporating health, functional status, and individual and socioeconomic aspects ${ }^{3}$; several studies have revealed its association with overall physical health, including oral health $^{4-11)}$. Other investigators have reported oral health's influence on elders' quality of life, demonstrating increasing interest in oral health. According to studies, elders with poor oral health have severe depression and low quality of life, which can be ameliorated by appropriate care $^{12)}$.

A 2006 systematic review revealed that temporomandibular disorder, poor oral health, dissatisfaction with teeth and mouth, and oral dryness diminished oral health-related quality of life, which was low among people without teeth ${ }^{13)}$. Moreover, oral health-related quality of life typically improves upon receipt of dental implants or dentures ${ }^{14,15)}$. Likewise, studies on oral health-related quality of life have typically focused on its association with the oral health state. According to many investigators, good oral health is essential for good oral health-related quality of life. Despite this relationship, the quality of life index measures subjective judgments. Psychological and cognitive aspects must also be considered, and improving quality of life requires multi-dimensional efforts. Jensen et al. ${ }^{16)}$ reported oral health-related quality of life's association with the perceived need for dental treatment, and negative association with self-rated health, mental health, number of teeth, and cognitive status, also describing how mental and cognitive states relate oral health-related quality of life.

Xerostomia is common among elders and complicates eating and word pronunciation ${ }^{17)}$. Elders secrete about half the amount of saliva as normal adults do; therefore, xerostomia poses serious problems. Furthermore, many medications administered for chronic degenerative diseases in elders decrease saliva production and cause xerostomia ${ }^{17,18)}$. Moreover, a close association between xerostomia and psychological factors is reportedly common among elders. Its relationships with oral health-related quality of life ${ }^{19)}$ and depression have been reported among some South Korean elders $^{20)}$.

To analyze psychological factors affecting oral healthrelated quality of life, we analyzed the correlations between depression, cognitive function, oral health state, ability to perform activities of daily living (ADL), oral dryness symptoms, and oral health-related quality of life. Moreover, this study will provide a reference for plans aimed at improving oral health-related quality of life, by examining the related factors influencing elders' oral health-related quality of life.

\section{Materials and Methods}

\section{Study design}

A cross-sectional study was conducted to determine oral health-related quality of life's relationships with depression, cognitive function, oral dryness symptoms, and the ability to perform ADL. An elderly community sample, who participated in a dementia examination project for elders with suspected dementia in 2013, provided the data. The dementia examination project aims to improve the quality of life of elderly people with dementia and their families by conducting early screening of dementia for those aged 60 and older who are at high risk of dementia.

The dementia examinations were performed from March 28 to November 6, 2013; psychiatrists, psychiatric nurses, and dental hygienists visited clinics in the participating regions for examination and questionnaire administration. Psychiatrists, psychiatric nurses examinated various scales and oral health state examination was conducted by the three dental hygienists and one dentist. Before conducting the study, four examiners conducted the study once a week for 2 weeks. We examined the agreement test for the oral health state. The Cronbach alpha among the examiners was 0.899 , indicating a high level of agreement.

\section{Study participants}

Elders ( $\geq 60$ years; $n=313$ ) suspected of dementia had participated dementia examination program conducted in three regions (Hoengseong, Yeongwol, Pyeongchang) in Gangwon province, South Korea in 2013. The sample size was calculated as 237 in the regression model using $\mathrm{G}^{*}$ power 3.1.9.2 program. The dropout rate was about 10 percent; therefore, 265 persons were selected for the study. These 265 received dementia- and oral health-related examinations and questionnaires. We excluded the responses of four participants diagnosed with moderate/ 
severe dementia and one with insincere responses likely to affect the results significantly. Therefore, 260 elders were included for analysis in this study.

\section{Study variable}

\section{1) General characteristics}

Sex, age, education level, health insurance, marital status, living arrangement, occupation, cognitive status, and systemic disease were included as general participant characteristics.

\section{2) Cognitive function}

Psychiatrists examined cognitive function using the clinical dementia rating $(\mathrm{CDR})^{21)}$. CDR is a global scale developed to clinically denote the presence of dementia of Alzheimer type (DAT) and stage its severity. Participants were classified into three categories, namely, no dementia, mild cognitive impairment, and mild dementia.

\section{3) Ability to perform ADL}

The Barthel activities of daily living scale (ADLS) ${ }^{22)}$, which included 10 items regarding defecating and urinating alone, examined the ability to perform ADL. The Barthel Index measures the degree of assistance required by an individual on 10 items of mobility and self care ADL. Ten variables are Bathing, feeding, grooming, dressing, bowels, bladder, toilet use, transfer (bed to chair and back), mobility (on level surfaces), and stairs. The maximum possible score was 20 , the higher one's score, the closer one was to being normal.

\section{4) Geriatric depression}

The geriatric depression scale (GDS) assessed geriatric depression. The GDS contains 30 yes/no questions, yielding 30 points (range: 0 to 30); a higher score indicated higher levels of depression. According to Brink et al. ${ }^{23)}$, scores between 0 and 9 indicated a normal state; 10 30 indicated depression. The score was analyzed as a continuous variable.

\section{5) Oral health state}

The Kayser-Jones' Brief Oral Health Status Examination $(\text { BOHSE })^{24)}$ evaluated participants' oral health state through 10 items, including those evaluating the lymphatic glands, lips, tongue, saliva, state of teeth, and oral hygienic conditions. The score ranged from 0 (very poor oral state) to 2 (normal oral state), depending on severity level (score range: $0 \sim 20$ ). A high score indicated poor oral health.

\section{6) Oral dryness}

A five-item questionnaire on, among others, the presence of oral dryness when eating food, sleeping at night, and performing daily activities, assessed oral dryness ${ }^{25)}$. The questions were chosen by Watt et al. ${ }^{11}$; the questionnaire's reliability and validity were verified by experts. Possible answers were either "yes" or "no" (score range: 0 $\sim 5$ ). A higher score indicated a drier oral state ${ }^{11,25)}$.

\section{7) Oral health-related quality of life}

The Korean version of the Geriatric Oral Health Assessment Index (GOHAI) assessed oral health-related quality of life. Atchison and Dolan ${ }^{26)}$ developed the original GOHAI in 1990; its credibility and validity were verified by Shin and Jung ${ }^{25)}$. The GOHAI comprised 12 items, yielding 36 points in total. A higher score indicated higher quality of life.

\section{Analysis}

Data analysis was performed using SPSS ver. 20.0 (IBM Corp., Armonk, NY, USA). The scores on the GDS, ADLS, BOHSE, oral dryness, and GOHAI were analyzed according to general characteristics, using independent t-tests and one-way analysis of variance. Bivariate correlation analysis was conducted to determine the correlations between all variables, and multiple regression analysis verified the factors related to oral health-related quality of life. Significance was set at $\mathrm{p}<0.05$.

\section{Results}

1. GDS, ADLS, BOHSE, oral dryness, and GOHAI scores according to general characteristics

Participants who showed severe depression symptoms were poorly educated, living alone, and unemployed.

Depression symptoms showed statistically significant 
differences according to education level. Participants with below elementary school graduation and high school graduation or above 14.9 and 9.2, respectively $(\mathrm{p}<$ 0.001). Participants diagnosed with mild cognitive impairment and dementia had more severe depressive symptoms than did those with a normal cognitive state.

Oral health state showed statistically significant differences according to cognitive function. Participants with mild

Table 1. ADL, GDS, BOHSE, Oral Dryness, and GOHAI by General Characteristics

\begin{tabular}{|c|c|c|c|c|c|c|c|}
\hline Variable & Category & $\mathrm{n}$ & $\mathrm{ADL}$ & GDS & BOHSE & Oral dryness & GOHAI \\
\hline \multirow[t]{3}{*}{$\operatorname{Sex}^{c}$} & Male & $91(35.0)$ & $19.4 \pm 1.5$ & $11.6 \pm 7.8$ & $5.2 \pm 2.7$ & $0.9 \pm 1.2$ & $28.7 \pm 7.7$ \\
\hline & Female & $169(65.0)$ & $19.1 \pm 2.0$ & $14.6 \pm 8.4$ & $4.8 \pm 2.7$ & $1.6 \pm 1.7$ & $26.1 \pm 9.2$ \\
\hline & p-value & & 0.187 & 0.006 & 0.213 & $<0.001$ & 0.020 \\
\hline \multirow[t]{5}{*}{$\operatorname{Age}(y)^{d}$} & $60 \sim 69$ & $33(12.7)$ & $19.6 \pm 0.7$ & $12.7 \pm 8.4$ & $4.4 \pm 3.0$ & $1.4 \pm 1.4$ & $27.9 \pm 7.1$ \\
\hline & $70 \sim 79$ & $165(63.5)$ & $19.2 \pm 1.8$ & $13.6 \pm 8.5$ & $4.8 \pm 2.6$ & $1.3 \pm 1.5$ & $27.5 \pm 8.7$ \\
\hline & $80 \sim 89$ & 57 (21.9) & $19.0 \pm 2.4$ & $14.4 \pm 8.2$ & $5.5 \pm 2.9$ & $1.6 \pm 1.8$ & $25.5 \pm 9.3$ \\
\hline & $\geq 90$ & $5(1.9)$ & $19.4 \pm 0.9$ & $9.6 \pm 4.9$ & $6.0 \pm 2.1$ & $1.6 \pm 2.3$ & $24.0 \pm 12.4$ \\
\hline & p-value & & 0.488 & 0.566 & 0.180 & 0.637 & 0.393 \\
\hline \multirow[t]{5}{*}{ Education level $^{\mathrm{d}}$} & $<$ Elementary school & $176(67.7)$ & $19.1 \pm 2.0$ & $14.9 \pm 8.2^{\mathrm{a}}$ & $5.0 \pm 2.8$ & $1.6 \pm 1.7^{\mathrm{a}}$ & $25.8 \pm 9.1^{\mathrm{a}}$ \\
\hline & Elementary school & $50(19.2)$ & $19.5 \pm 1.1$ & $11.6 \pm 8.3^{\mathrm{ab}}$ & $5.2 \pm 2.6$ & $1.3 \pm 1.5^{\mathrm{ab}}$ & $28.9 \pm 8.1^{\mathrm{ab}}$ \\
\hline & Middle school & $14(5.4)$ & $19.6 \pm 0.7$ & $10.0 \pm 6.3^{\mathrm{ab}}$ & $4.7 \pm 2.6$ & $0.4 \pm 0.6^{\mathrm{ab}}$ & $28.1 \pm 8.7^{\mathrm{ab}}$ \\
\hline & $\geq$ High school & $20(7.7)$ & $19.3 \pm 2.4$ & $9.2 \pm 7.9^{\mathrm{b}}$ & $3.9 \pm 2.1$ & $0.5 \pm 1.2^{\mathrm{b}}$ & $32.1 \pm 4.0^{\mathrm{b}}$ \\
\hline & $\mathrm{p}$-value & & 0.428 & 0.001 & 0.318 & 0.003 & 0.005 \\
\hline \multirow{3}{*}{$\begin{array}{l}\text { Health } \\
\text { insurance }^{c}\end{array}$} & Medical insurance & $234(90.0)$ & $19.3 \pm 1.7$ & $13.4 \pm 8.3$ & $5.0 \pm 2.7$ & $1.4 \pm 1.6$ & $26.8 \pm 9.0$ \\
\hline & Medical care & $26(10.0)$ & $18.7 \pm 2.6$ & $14.7 \pm 9.0$ & $4.4 \pm 2.9$ & $0.8 \pm 1.2$ & $29.5 \pm 5.6$ \\
\hline & p-value & & 0.235 & 0.482 & 0.275 & 0.016 & 0.034 \\
\hline \multirow[t]{4}{*}{ Marital status $^{\mathrm{d}}$} & Married & $127(48.8)$ & $19.4 \pm 1.4$ & $12.1 \pm 7.9$ & $4.8 \pm 2.7$ & $1.1 \pm 1.3$ & $28.3 \pm 7.4$ \\
\hline & Divorce/widowed/unmarried & $131(50.4)$ & $19.1 \pm 2.2$ & $15.0 \pm 8.5$ & $5.0 \pm 2.7$ & $1.6 \pm 1.8$ & $25.6 \pm 9.7$ \\
\hline & Others & $2(0.8)$ & $19.5 \pm 0.7$ & $11.0 \pm 8.5$ & $7.5 \pm 0.7$ & $1.0 \pm 0.0$ & $36.0 \pm 0.0$ \\
\hline & p-value & & 0.509 & 0.019 & 0.308 & 0.065 & 0.015 \\
\hline \multirow{6}{*}{$\begin{array}{l}\text { Living } \\
\text { arrangement }^{\mathrm{d}}\end{array}$} & Alone & $91(35.0)$ & $19.2 \pm 1.7$ & $15.7 \pm 8.2$ & $5.0 \pm 2.9$ & $1.5 \pm 1.8$ & $24.9 \pm 9.9$ \\
\hline & With spouse only & $88(33.8)$ & $19.4 \pm 1.1$ & $11.7 \pm 8.1$ & $4.7 \pm 2.7$ & $1.1 \pm 1.3$ & $28.8 \pm 7.6$ \\
\hline & With family (without spouse) & $35(13.5)$ & $19.1 \pm 2.8$ & $12.6 \pm 8.6$ & $5.2 \pm 2.6$ & $1.9 \pm 1.9$ & $26.7 \pm 10.2$ \\
\hline & With family (with spouse) & $39(15.0)$ & $19.4 \pm 0.8$ & $13.2 \pm 7.7$ & $5.0 \pm 2.4$ & $1.2 \pm 1.3$ & $28.0 \pm 6.5$ \\
\hline & Others & $7(2.7)$ & $16.3 \pm 5.1$ & $15.7 \pm 1.0$ & $5.1 \pm 2.9$ & $0.7 \pm 0.8$ & $28.6 \pm 5.2$ \\
\hline & p-value & & 0.001 & 0.023 & 0.872 & 0.055 & 0.039 \\
\hline \multirow[t]{3}{*}{ Occupation $^{\mathrm{c}}$} & Yes & $93(35.8)$ & $19.7 \pm 0.6$ & $12.1 \pm 8.1$ & $5.0 \pm 2.6$ & $1.3 \pm 1.5$ & $27.9 \pm 8.2$ \\
\hline & No & $167(64.2)$ & $19.0 \pm 2.2$ & $14.4 \pm 8.4$ & $4.9 \pm 2.8$ & $1.4 \pm 1.6$ & $26.5 \pm 9.0$ \\
\hline & p-value & & $<0.001$ & 0.040 & 0.959 & 0.828 & 0.220 \\
\hline \multirow[t]{4}{*}{ Cognitive status ${ }^{\mathrm{d}}$} & Normal & $56(21.5)$ & $19.6 \pm 0.7$ & $9.7 \pm 6.9^{\mathrm{a}}$ & $4.2 \pm 2.5^{\mathrm{a}}$ & $1.0 \pm 1.3$ & $28.5 \pm 8.8$ \\
\hline & Mild cognitive impairment & $109(42.0)$ & $19.2 \pm 2.0$ & $14.6 \pm 8.2^{\mathrm{b}}$ & $5.0 \pm 2.6^{\mathrm{a}}$ & $1.5 \pm 1.5$ & $26.8 \pm 8.2$ \\
\hline & Mild dementia & $95(36.5)$ & $19.0 \pm 2.1$ & $14.6 \pm 8.7^{\mathrm{b}}$ & $5.3 \pm 2.9^{\mathrm{a}}$ & $1.5 \pm 1.8$ & $26.5 \pm 9.4$ \\
\hline & p-value & & 0.115 & $<0.001$ & 0.049 & 0.206 & 0.360 \\
\hline \multirow{3}{*}{$\begin{array}{l}\text { Hypertension } \\
\text { status }^{c}\end{array}$} & Yes & $151(58.1)$ & $19.0 \pm 2.3$ & $14.5 \pm 8.1$ & $4.9 \pm 2.8$ & $1.5 \pm 1.7$ & $26.3 \pm 8.7$ \\
\hline & No & 109 (41.9) & $19.6 \pm 0.9$ & $12.3 \pm 8.5$ & $5.0 \pm 2.6$ & $1.2 \pm 1.5$ & $28.0 \pm 8.8$ \\
\hline & p-value & & 0.002 & 0.032 & 0.741 & 0.106 & 0.138 \\
\hline \multirow[t]{3}{*}{ Diabetes status ${ }^{c}$} & Yes & $56(21.5)$ & $19.3 \pm 1.9$ & $14.8 \pm 8.1$ & $4.8 \pm 2.7$ & $1.1 \pm 1.3$ & $27.3 \pm 8.6$ \\
\hline & No & $204(78.5)$ & $19.2 \pm 1.8$ & $13.2 \pm 8.4$ & $5.0 \pm 2.7$ & $1.5 \pm 1.7$ & $27.0 \pm 8.8$ \\
\hline & p-value & & 0.902 & 0.209 & 0.565 & 0.072 & 0.801 \\
\hline Total & & $260(100.0)$ & $19.2 \pm 1.8$ & $13.6 \pm 8.3$ & $4.9 \pm 2.7$ & $1.4 \pm 1.6$ & $2.3 \pm 0.7$ \\
\hline
\end{tabular}

Values are presented as $\mathrm{n}(\%)$ or mean \pm standard deviation.

ADLS: activities of daily living scale, GDS: geriatric depression scale, BOHSE: Brief Oral Health Status Examination, GOHAI: Geriatric Oral Health Assessment Index.

${ }^{a, b}$ by post hoc Scheffe' tests means with same letters are not significantly different, 'Independent t-test, 'one-way ANOVA. 
cognitive impairment and mild dementia scored 5.0 and 5.3 , respectively, and those with normal cognitive function scored 4.2, indicating a poorer state of oral health, as cognitive function declined $(\mathrm{p}=0.049)$ (Table 1$)$.

\section{Correlations between GDS, ADLS, BOHSE,} and GOHAI scores

GOHAI had a significant positive correlation with ADLS ( $r=0.236, p<0.01)$, a significant positive correlation with negative with GDS $(\mathrm{r}=-0.521, \mathrm{p}<0.01)$, dryness $(\mathrm{r}=$ $-0.523, \mathrm{p}<0.01)$, the correlation coefficient for GOHAI scores and oral dryness was the highest. However, the BOHSE $(r=-0.098, p>0.05)$ and GOHAI scores were not significantly correlated (Table 2).

\section{Factors related to the GOHAI scores}

The factors correlated with GOHAI were inserted together as independent variables, and the enter method was used. GDS and oral dryness scores were significantly related with GOHAI scores; the adjusted explanatory power was $40.2 \%$.

Based on stepwise regression analysis, all variables, excluding oral dryness and GDS, were removed; the two remaining variables were significant factors influencing GOHAI scores. The adjusted explanatory power of the reduced model was $40.2 \%$ (Table 3 ).

\section{Discussion}

Our objective was to understand the effects of cognitive function, ability to perform $\mathrm{ADL}$, depression, oral dryness,

Table 2. Correlation of ADLS, GDS, BOHSE, Oral Dryness, and GOHAI

\begin{tabular}{lccccc}
\hline & 1 & 2 & 3 & 4 & 5 \\
\hline 1. ADLS & 1 & & & & \\
2. GDS & $-0.324^{* *}$ & 1 & & & \\
3. BOHSE & -0.073 & 0.048 & 1 & 1 & \\
4. Oral dryness & $-0.146^{*}$ & $0.343^{* *}$ & $0.133^{*}$ & $-0.523^{* *}$ & 1 \\
5. GOHAI & $0.236^{* *}$ & $-0.521^{* *}$ & -0.098 & \\
\hline
\end{tabular}

Pearson's correlation analysis * $\mathrm{p}<0.05,{ }^{* *} \mathrm{p}<0.01$.

ADLS: activities of daily living scale, GDS: geriatric depression scale, BOHSE: Brief Oral Health Status Examination, GOHAI: Geriatric Oral Health Assessment Index.

Table 3. Factors Influencing Oral Health-Related Quality of Life in Elders (Multiple Linear Regression Model)

\begin{tabular}{lccrrr}
\hline & $\mathrm{B}$ & $\mathrm{SE}$ & $\beta$ & $\mathrm{t}$ & $\mathrm{p}$-value \\
\hline Full model (enter method) & & & & & \\
Sex & 0.899 & 1.041 & 0.049 & 0.865 & 0.388 \\
Age (y) & -0.028 & 0.074 & -0.020 & -0.380 & 0.704 \\
Education period (y) & 0.187 & 0.128 & 0.087 & 1.459 & 0.146 \\
Health insurance & 2.339 & 1.464 & 0.080 & 1.598 & 0.111 \\
ADLS & 0.323 & 0.245 & 0.068 & 1.321 & 0.188 \\
GDS & -0.379 & 0.057 & -0.361 & -6.599 & $<0.001$ \\
BOHSE & -0.011 & 0.163 & -0.003 & -0.066 & 0.947 \\
Oral dryness & -2.017 & 0.292 & -0.370 & -6.901 & $<0.001$ \\
Reduced model (stepwise method) & \multicolumn{2}{c}{$\mathrm{R}^{2}=0.421, \mathrm{R}_{\mathrm{adj}}^{2}=0.402(\mathrm{p}<0.001)$} & & \\
Oral dryness & -2.129 & 0.279 & -0.390 & -7.623 & $<0.001$ \\
GDS & -0.407 & 0.054 & -0.388 & -7.577 & $<0.001$
\end{tabular}

Multiple linear regression.

SE: standard error, ADLS: activities of daily living scale, GDS: geriatric depression scale, BOHSE: Brief Oral Health Status Examination. 
and oral health state on oral health-related quality of life among elders residing in South Korea. This study formed part of a dementia examination project for people with suspected dementia. However, $21.5 \%$ of participants were diagnosed as normal and $42.0 \%$ with mild cognitive impairment. Participants with severe dementia were excluded from analysis. Moreover, cognitive function changes did not yield significant differences in oral health-related quality of life. Therefore, cognitive function was not considered as an independent variable in the regression analysis.

Our results showed that female were more likely to experience depression symptoms than male; education and depression levels were also negatively associated. Further, people who were unemployed and living alone were more depressed than those who were not. These findings matched those of other studies. Generally, a higher rate of depression has been reported among female, compared to male; moreover, elders and those with a low income or living alone are more likely to experience depression ${ }^{18)}$. The BOHSE, developed for elderly people in nursing homes, assessed their oral health state. During the BOHSE assessment, we also considered tooth loss rate and frequency of oral soft tissue diseases, pain, contagious oral illnesses, and oral dryness.

We found that those with mild cognitive impairment or mild dementia had significantly poor oral health, similar to the result of another study on elders in nursing homes ${ }^{27}$. Subjective oral dryness was more common among female than male and did not differ according to age; however, those with low education levels were more likely to experience oral dryness. Furthermore, oral dryness was more prevalent among those with medical care than those with medical insurance; there was no difference between hypertensive and diabetic participants.

The Korean version of the GOHAI examined oral health-related quality of life; its credibility and validity were verified by Shin and Jung ${ }^{25)}$. Male had higher oral health-related quality of life than female. Further, married people and those with higher education levels and medical care, rather than medical insurance, had higher GOHAI scores. Other studies have also shown that lower education levels were related with lower GOHAI scores, similar to our study ${ }^{25,28)}$. However, in our study, unlike others, there were no correlations between any of the cognitive function levels and systematic diseases, and between employment status and GOHAI scores. Nevertheless, a previous study argued that elders with mild cognitive impairment might have scored higher on the GOHAI than healthy individuals because the perceived oral health state of those with mild cognitive impairment was possibly better than their actual state. Moreover, in that study, it was claimed that the examined cognitive level could have been dependent on the period during which it was measured, which necessitates regular examinations ${ }^{29)}$. Thus, cognitively impaired elders can be affected by their cognition level (i.e., unawareness of their health state) when describing their subjective feelings, which can influence various outcomes.

Based on the correlation analysis, the highest correlation was observed between oral dryness and GOHAI scores, followed by that between oral dryness and GDS. There were significant correlations among the ADLS ( $r=0.236$, $\mathrm{p}<0.01)$, GDS $(\mathrm{r}=-0.521, \mathrm{p}<0.01)$, dryness $(\mathrm{r}=-0.523$, $\mathrm{p}<0.01)$. However, the oral health state did not correlate with GOHAI scores, consistent with a previous study that identified the ability to perform ADL as a factor with no influence on oral health-related quality of life $\mathrm{e}^{30}$. In the regression analysis, oral health-related quality of life was influenced only by oral dryness and depression. The explanatory factor of $40.2 \%$ was relatively high. Unlike oral health examination by professionals, a subjective assessment of oral health-related quality of life was based on how much oral health subjectively affects quality of life and self-satisfaction levels. Therefore, our findings were possibly influenced by the examination of subjective feelings and discomfort due to one's psychological state and dryness, rather than the objective states. Similar to earlier studies, there were no correlations between sex, age, presence of systematic illness, and GOHAI scores.

Furthermore, participants compensating for loss of teeth functions with dentures typically had higher quality of life than before receiving the dentures ${ }^{25,31)}$. In another study, elders with dentures and good subjective oral health states had higher oral health-related quality of life, supporting our findings ${ }^{32)}$. However, some previous findings were 
incongruent with ours. In one study, marital status and the presence or absence of a systematic disease influenced oral health-related quality of life ${ }^{29)}$. According to some researchers, oral health-related quality of life influences depression and quality of life among elders, contrary to our study's hypothesis $^{33)}$.

The ability to perform ADL was significantly correlated with oral health-related quality of life in the correlation analysis, but not the multiple regression analysis. Measurement of the ability to perform ADL included activities related with oral health care. Therefore, it was predicted that oral health-related quality of life would decline when one was unable to perform such activities, but this was not observed. Moreover, the ability to perform ADL was not related with cognitive function. Other researchers have found that people with severe depressive symptoms were relatively less capable of performing everyday activities ${ }^{34)}$. Some of our participants were diagnosed with mild cognitive impairment and dementia, and did not have problems with the oral examinations and questionnaire completion; therefore, a study involving participants with a wider range of dementia symptoms should analyze more diverse effects of ADL and reach a credible conclusion.

Our participants resided in a small part of South Korea; therefore, the generalizability of our results is limited. Moreover, we could not consider all other factors possibly affecting oral health-related quality of life. However, to explain oral health-related quality of life, we analyzed descriptive factors, while considering mental health state and cognitive function in addition to oral health state. Therefore, we believe that this was a meaningful study. We also determined that efforts to positively relationship oral health-related quality of life should be multilateral, and not restricted to the mouth. Because the ageing population is steadily growing in number, it is important to seek ways to improve elders' quality of life and ensure their physical and mental health by analyzing various factors affecting their oral health-related quality of life.

In conclusion, the worse the oral dryness, the higher depression was low quality of life.

The results showed that to enhance elders' oral health-related quality of life, it is essential to not only improve their oral health state, but also relieve oral health problems, especially oral dryness, and take into consideration their psychological aspects. The results showed that to enhance elders' oral health-related quality of life, it is essential to not only improve their oral health state, but also relieve oral health problems, especially oral dryness, and take into consideration their psychological aspects.

\section{Notes}

\section{Conflict of interest}

No potential conflict of interest relevant to this article was reported.

\section{Ethical approval}

This study was conducted in full accordance with the World Medical Association Declaration of Helsinki (version 2008) and approved by the Research Ethics Committee of Yonsei University Wonju College of Medicine (Approval number: YWDR-14-9-025). The participants provided written informed consent. Data that could reveal participants' personal information or social status were not included during analysis.

\section{ORCID}

So-Jung Mun, https://orcid.org/0000-0002-5739-1319

Su-Kyung Park, https://orcid.org/0000-0002-0738-4786

Ji-Eun Heo, https://orcid.org/0000-0001-6449-5856

Da-Yee Jeung, https://orcid.org/0000-0003-4730-8814

Won-Gyoun Chung, https://orcid.org/0000-0003-2760-9732

Ma-I Choi, https://orcid.org/0000-0002-0088-469X

Hyun-Sun Jeon, https://orcid.org/0000-0003-0733-3871

\section{Acknowledgements}

This work was financially supported by a research grant from Yonsei University Wonju College of Medicine. The sponsor of the study had no role in the study design, conduct of the study, data collection, data interpretation or, preparation of the report.

\section{References}

1. KOSIS: Relief expenses and aging index. Retrieved October 
25, 2019, from http://kosis.kr/statHtml/statHtml.do?orgId= 101\&tblId=DT_1YL12501E\&vw_cd=MT_GTITLE01\&list_i $\mathrm{d}=101 \&$ seqNo=\&lang_mode=ko\&language $=$ kor\&obj_var_id $=\& \mathrm{itm} \_\mathrm{id}=\&$ conn_path=MT_GTITLE01 (2019, October 10).

2. Development of the World Health Organization WHOQOLBREF quality of life assessment. The WHOQOL Group. Psychol Med 28: 551-558, 1998. https://doi.org/10.1017/s0033291798006667

3. Bowling A, Banister D, Sutton S, Evans O, Windsor J: A multidimensional model of the quality of life in older age. Aging Ment Health 6: 355-371, 2002. https://doi.org/10.1080/1360786021000006983

4. Akifusa S, Soh I, Ansai T, et al.: Relationship of number of remaining teeth to health-related quality of life in communitydwelling elderly. Gerodontology 22: 91-97, 2005. https://doi.org/10.1111/j.1741-2358.2005.00059.x

5. Cassolato SF, Turnbull RS: Xerostomia: clinical aspects and treatment. Gerodontology 20: 64-77, 2003. https://doi.org/10.1111/j.1741-2358.2003.00064.x

6. Gall TL, Evans DR, Howard J: The retirement adjustment process: changes in the well-being of male retirees across time. J Gerontol B Psychol Sci Soc Sci 52: 110-117, 1997. https://doi.org/10.1093/geronb/52b.3.p110

7. Almoznino G, Aframian DJ, Sharav Y, Sheftel Y, Mirzabaev A, Zini A: Lifestyle and dental attendance as predictors of oral health-related quality of life. Oral Dis 21: 659-666, 2015. https://doi.org/10.1111/odi.12331

8. Matthias RE, Atchison KA, Lubben JE, De Jong F, Schweitzer SO: Factors affecting self-ratings of oral health. J Public Health Dent 55: 197-204, 1995. https://doi.org/10.1111/j.1752-7325.1995.tb02370.x

9. Sim SJ: Association between oral health status and perceived general health (EuroQol-5D). J Dent Hyg Sci 14: 364-370. 2014. https://doi.org/10.17135/jdhs.2014.14.3.364

10. Strauss RP, Hunt RJ: Understanding the value of teeth to older adults: influences on the quality of life. J Am Dent Assoc 124: 105-110, 1993.

https://doi.org/10.14219/jada.archive.1993.0019

11. Watt RG, Harnett R, Daly B, et al.: Evaluating oral health promotion: need for quality outcome measures. Community Dent Oral Epidemiol 34: 11-17, 2006. https://doi.org/10.1111/j.1600-0528.2006.00257.x

12. Jang SH, Choi MH: Evaluation of the qualite of life related to oral health among elderly people in some elderly care facilities by OHIP-14. J Korean Soc Dent Hyg 11: 475-487.

13. Ástvaldsdóttir Á, Boström AM, Davidson T, et al.: Oral health and dental care of older persons-a systematic map of systematic reviews. Gerodontology 35: 290-304, 2018. https://doi.org/10.1111/ger.12368

14. Gerritsen AE, Allen PF, Witter DJ, Bronkhorst EM, Creugers NH: Tooth loss and oral health-related quality of life: a systematic review and meta-analysis. Health Qual Life Outcomes 8: 126, 2010. https://doi.org/10.1186/1477-7525-8-126

15. Shigli K, Hebbal M: Assessment of changes in oral health-related quality of life among patients with complete denture before and 1 month post-insertion using Geriatric Oral Health Assessment Index. Gerodontology 27: 167-173, 2010. https://doi.org/10.1111/j.1741-2358.2009.00323.x

16. Jensen PM, Saunders RL, Thierer T, Friedman B: Factors associated with oral health-related quality of life in community-dwelling elderly persons with disabilities. J Am Geriatr Soc 56: 711-717, 2008. https://doi.org/10.1111/j.1532-5415.2008.01631.x

17. Ship JA, Pillemer SR, Baum BJ: Xerostomia and the geriatric patient. J Am Geriatr Soc 50: 535-543, 2002. https://doi.org/10.1046/j.1532-5415.2002.50123.x

18. von Bültzingslöwen I, Sollecito TP, Fox PC, et al.: Salivary dysfunction associated with systemic diseases: systematic review and clinical management recommendations. Oral Surg Oral Med Oral Pathol Oral Radiol Endod 103 Suppl: S57.e1-15, 2007. https://doi.org/10.1016/j.tripleo.2006.11.010

19. Locker D: Dental status, xerostomia and the oral health-related quality of life of an elderly institutionalized population. Spec Care Dentist 23: 86-93, 2003. https://doi.org/10.1111/j.1754-4505.2003.tb01667.x

20. Jang JH, Kim SH: The relationship between xerostomia and depression in elderly people. Korean J Health Educ Promot 24: 51-60, 2007.

21. Morris JC: The Clinical Dementia Rating (CDR): current version and scoring rules. Neurology 43: 2412-2414, 1993. https://doi.org/10.1212/wnl.43.11.2412-a

22. Wade DT, Collin C: The Barthel ADL Index: a standard measure of physical disability? Int Disabil Stud 10: 64-67, 1998. https://doi.org/10.3109/09638288809164105 
23. Brink TL, Yesavage JA, Lum O, Heersema PH, Adey M, Rose TL: Screening tests for geriatric depression. Clin Gerontol 1: 37-43, 1982. https://doi.org/10.1300/J018v01n01_06

24. Kayser-Jones J, Bird WF, Paul SM, Long L, Schell ES: An instrument to assess the oral health status of nursing home residents. Gerontologist 35: 814-824, 1995. https://doi.org/10.1093/geront/35.6.814

25. Shin SJ, Jung SH: A Korean version of the Geriatric Oral Health Assessment Index (GOHAI) in elderly populations: validity and reliability. J Korean Acad Oral Health 35: 187-195, 2011.

26. Atchison KA, Dolan TA: Development of the geriatric oral health assessment index. J Dent Educ 54: 680-687, 1990.

27. Almomani F, Hamasha AA, Williams KB, Almomani M: Oral health status and physical, mental and cognitive disabilities among nursing home residents in Jordan. Gerodontology 32: 90-99, 2015. https://doi.org/10.1111/ger.12053

28. Tsakos G, Sheiham A, Iliffe S, et al.: The impact of educational level on oral health-related quality of life in older people in London. Eur J Oral Sci 117: 286-292, 2009. https://doi.org/10.1111/j.1600-0722.2009.00619.x

29. Zuluaga DJ, Montoya JA, Contreras CI, Herrera RR: Association between oral health, cognitive impairment and oral health-related quality of life. Gerodontology 29: e667-e673, 2012. https://doi.org/10.1111/j.1741-2358.2011.00542.x

30. Han JH, Yom YH: Effects of eating habits, activities of daily living and health behaviors on oral health related-quality of life in elderly persons. J Korean Acad Fundam Nurs 19: 179-189, 2012. https://doi.org/10.7739/jkafn.2012.19.2.179

31. Fuentes-García A, Lera L, Sánchez H, Albala C: Oral health-related quality of life of older people from three South American cities. Gerodontology 30: 67-75, 2013. https://doi.org/10.1111/j.1741-2358.2012.00649.x

32. Silva AE, Demarco FF, Feldens CA: Oral health-related quality of life and associated factors in Southern Brazilian elderly. Gerodontology 32: 35-45, 2015. https://doi.org/10.1111/ger.12050

33. Lee HS, Kim CM: Effects of oral health impact profile (OHIP) on depression and quality of life among communitydwelling Korean elderly persons. J Korean Acad Community Health Nurs 23: 338-346, 2012. https://doi.org/10.12799/jkachn.2012.23.3.338

34. Wada T, Ishine M, Sakagami T, et al.: Depression in Japanese community-dwelling elderly--prevalence and association with ADL and QOL. Arch Gerontol Geriatr 39: 15-23, 2004. https://doi.org/10.1016/j.archger.2003.12.003 